\title{
Effects of a small-scale, abandoned gold mine on the geochemistry of fine stream-bed and floodplain sediments in the Horsefly River watershed, British Columbia, Canada
}

\author{
Deirdre E. Clark ${ }^{1, *}$, Marjolein F. A. Vogels ${ }^{1}$, Marcel van der Perk ${ }^{1}$, Philip N. Owens ${ }^{2}$ and \\ ElLen L. PetTicrew ${ }^{3}$ \\ 1 Department of Physical Geography, Utrecht University, P.O. Box 80115, 3508, TC, Utrecht, The Netherlands \\ 2 Environmental Science Program and Quesnel River Research Centre, University of Northern British Columbia, \\ 3333 University Way, Prince George, BC, V2N 4Z9, Canada \\ 3 Geography Program and Quesnel River Research Centre, University of Northern British Columbia, 3333 \\ University Way, Prince George, BC, V2N 4Z9, Canada
}

[Received 4 May 2014; Accepted 20 January 2015; Associate Editor: T. Rinder]

\section{ABSTRACT}

Mining is known to be a major source of metal contamination for fluvial systems worldwide. Monitoring and understanding the effects on downstream water and sediment quality is essential for its management and to mitigate against detrimental environmental impacts. This study aimed to examine the effects of the small-scale, abandoned, hydraulic Black Creek gold mine on the geochemical content of fine $(<63 \mu \mathrm{m})$ stream bed and floodplain sediment in the Horsefly watershed (British Columbia, Canada), which is a part of the Quesnel River basin. Concentrations of As, Cd, Se and Zn were determined by aqua regia digestion and the modified BCR (European Community Bureau of Reference) sequential extraction procedure followed by inductively coupled plasma-optical emission spectroscopy or inductively coupled plasma-mass spectrometry. Age-depth models for the floodplain cores were constructed using excess $\mathrm{Pb}-210$ and Cs-137 activity concentration profiles. The results show that the mine caused local As contamination of the Horsefly River floodplain sediment during the first years of operation, but at present the contamination is mainly contained in the Black Creek. Present-day and recent concentrations of $\mathrm{Cd}$, Se and $\mathrm{Zn}$ in the Horsefly River are elevated and this is probably derived from other upstream mining activities. The spatial and temporal changes in heavymetal concentrations suggest a slight, but not particularly widespread, mining effect on the finesediment geochemistry in the Horsefly River system.

KEYwords: gold mine, sediment geochemistry, pollution, environment, British Columbia, Canada.

\section{Introduction}

Active and abandoned mine sites represent a major environmental problem for fluvial systems worldwide (Du Laing et al., 2007, 2009) and the related pollution can decrease water and sediment quality, thereby impacting aquatic ecosystems and human health. Mining exposes metal-bearing

* E-mail: dec2@hi.is

DOI: 10.1180/minmag.2014.078.6.16 sediments, which are then transported by surface waters and redeposited downstream (Luoma and Rainbow, 2008; van der Perk, 2013). High concentrations of metals in aquatic systems can be toxic for aquatic biota (Morel, 1983) and

This paper is published as part of a special issue in Mineralogical Magazine, Vol. 78(6), 2014 entitled 'Mineral-fluid interactions: scaling, surface reactivity and natural systems'. 
oxidation processes linked to surface mining could generate highly acidic discharges (Lin et al., 2005). Roughly $90 \%$ of heavy metals deposited in aquatic systems are found in the particulate form, especially in the fine $(<63 \mu \mathrm{m})$ sediment fraction (Hale, 1994; Horowitz, 1985; Loring, 1991; Luoma and Rainbow, 2008; van der Perk, 2013).

Canada has $7 \%$ of the world's renewable freshwater (Environment Canada, 2014) and is one of the world's top producers of metal resources, such as U, Au and $\mathrm{Zn}$ (Brown, 2002). In British Columbia, mining has been prevalent in the interior region since the 1850s (BC Heritage Rivers Program, 2014; Horsefly Historical Society, 1981). Mining activities are generally characterized by the diversion and pollution of water, and mine drainage is one of the province's main sources of chemical threats to surface- and groundwater quality (Environment Canada and Ministry of Environment, Lands and Parks, 1993). Environmental risks in a mine's area of influence are of particular concern as many rivers in British Columbia are major spawning habitats for several salmon species (Albers and Petticrew, 2012; BC Heritage Rivers Program, 2014).

A recent study by Smith and Owens (2014) found that historic and active mining activities in the Quesnel River basin in British Columbia have an influence on sediment-associated metals and nutrients, with elevated concentrations of $\mathrm{Se}, \mathrm{Cu}$ and As. They also identified that floodplains and other areas of sediment deposition may be storing contaminated sediment in the Quesnel River basin. Other research by Karimlou (2011) and van Lipzig (2011) also determined that active mining (e.g. from the Mount Polley mine; Fig. 1) influences the fine-sediment geochemistry of the Quesnel River basin. However, there are few studies in this region on the impacts of abandoned mines.

Given the evidence of the part played by active mining in sediment contamination, the objective of the present study was to determine if there are lasting spatial and temporal effects of mining on fine-sediment geochemistry after mine operations ceased in and around the extraction site as well as along the downstream channel system (e.g. channel and floodplain). For this, we selected the abandoned Black Creek mine in the Horsefly watershed, British Columbia $\left(52^{\circ} 18^{\prime} 45^{\prime \prime} \mathrm{N} /\right.$ $121^{\circ} 5^{\prime} 34^{\prime \prime} \mathrm{W}$; Fig. 1), as a suitable case study area. The Black Creek mine is a small-scale hydraulic gold mine situated near a stream, as was the case historically for many such mines. It was intermittently active from the 1920 s to 1980 s (BC Geological Survey, 2014). Figure 1 also shows other mines and mineral prospects in the study area. This work will additionally provide a baseline for selected heavy-metal concentrations to support potential future work in the region, especially given the recent increase in mining activities in central and northern British Columbia. Such work is particularly timely given the recent failure of the Mount Polley Mine's tailings pond, which is located in the Quesnel River basin (Fig. 1), and the urgent need for baseline data.

\section{Methods}

\section{Study area}

The study area focuses on an abandoned gold mine next to Black Creek, $2 \mathrm{~km}$ upstream from the Horsefly River. The Horsefly basin $\left(2983 \mathrm{~km}^{2}\right)$ is located within the Central Interior region near the Cariboo Range of the Columbia Mountains, and is part of the larger Quesnel watershed (Gilbert and Desloges, 2012). The region has a humid continental climate according to the Köppen climate system, and the annual precipitation, as recorded by the $\mathrm{BC}$ Forest Service in Horsefly, is $564 \mathrm{~mm}$. Most of the Quesnel basin is frozen for at least 5-6 months of the year and annual temperatures are typically below $-30^{\circ} \mathrm{C}$. River flows are dominated by the annual freshet (flows associated with the spring thaw and the melting of snow and ice) and peak flows occur between late May and early July (Smith and Owens, 2014).

The region's dominant rock types are mafic volcanic rocks of calc-alkaline to alkaline affinity and the stratigraphic succession consists of mainly pyroxene-phyric basaltic flows, flow breccia, debris, flow or lahar deposits and locally derived epiclastic rocks (Panteleyev and Hancock, 1988). The occurrence of Ag and other metals (e.g. $\mathrm{Cu}, \mathrm{Pb}, \mathrm{Zn}$ ) found in the area's sediments is probably because of supergene leaching of $\mathrm{Ag}$ dispersed within massive sulfides by deep weathering followed by erosion (BC Geological Survey, 2014). The product of supergene enrichment is the source of the placer deposits that form the foundation for today's mining activities.

\section{Sampling and laboratory methods}

Sampling sites were selected based on accessibility along the Black Creek and Horsefly River 

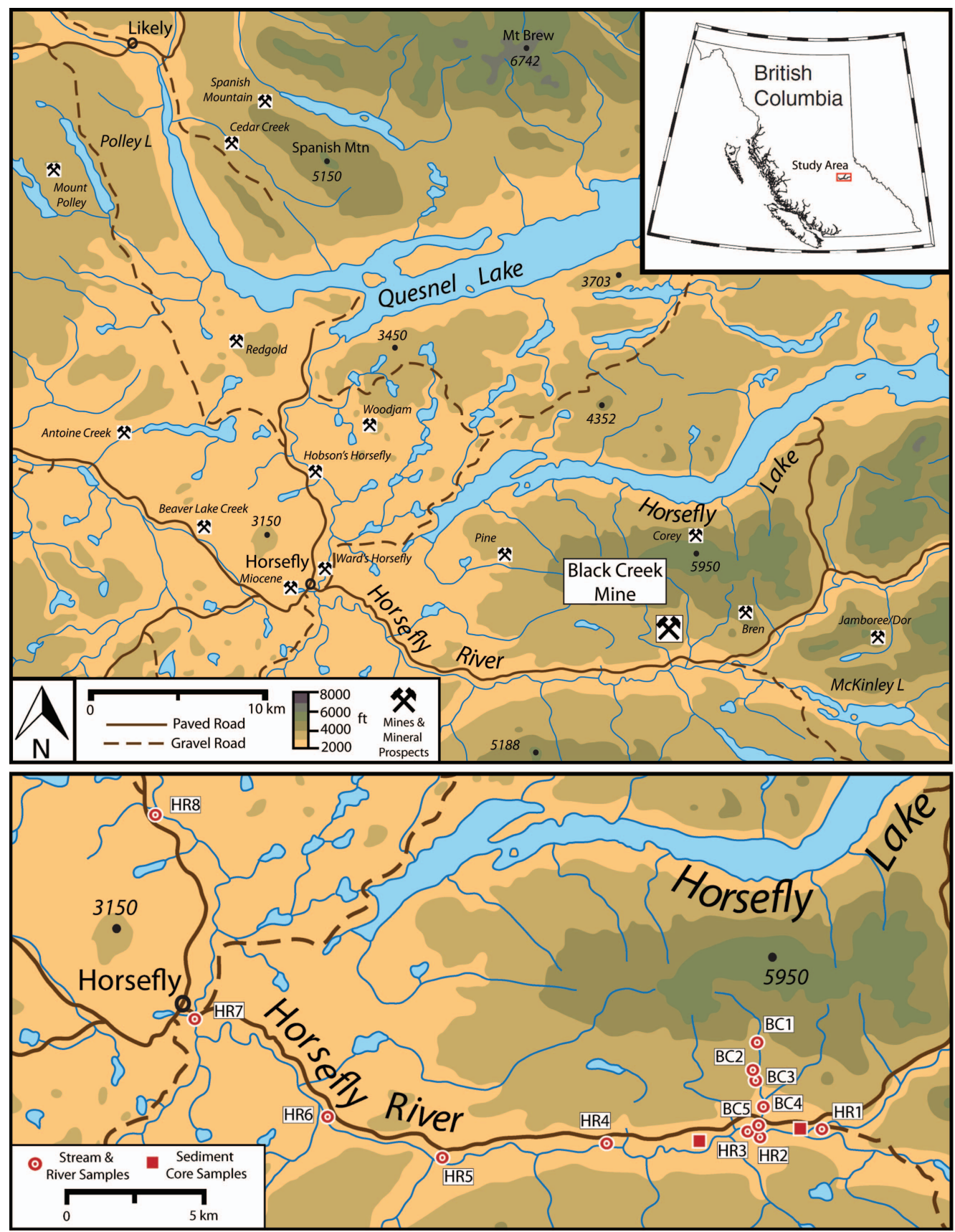

FIG. 1. Study area of Horsefly River watershed in British Columbia, Canada (Bailey, 1990; BC Geological Survey, 2014; map modified from Surveys and Mapping Branch, 1976) (above) and sample locations (below).

and sampling was conducted in August and September 2012 (Table 1). Stream-bed sediment samples were collected at 13 sites (Fig. 1) at key sediment storage locations in a downstream direction up to $50 \mathrm{~km}$ away from the mine to assess the spatial variation in sediment 
DEIRDRE E. CLARK ET AL.

TABLE 1. Description of samples and their locations.

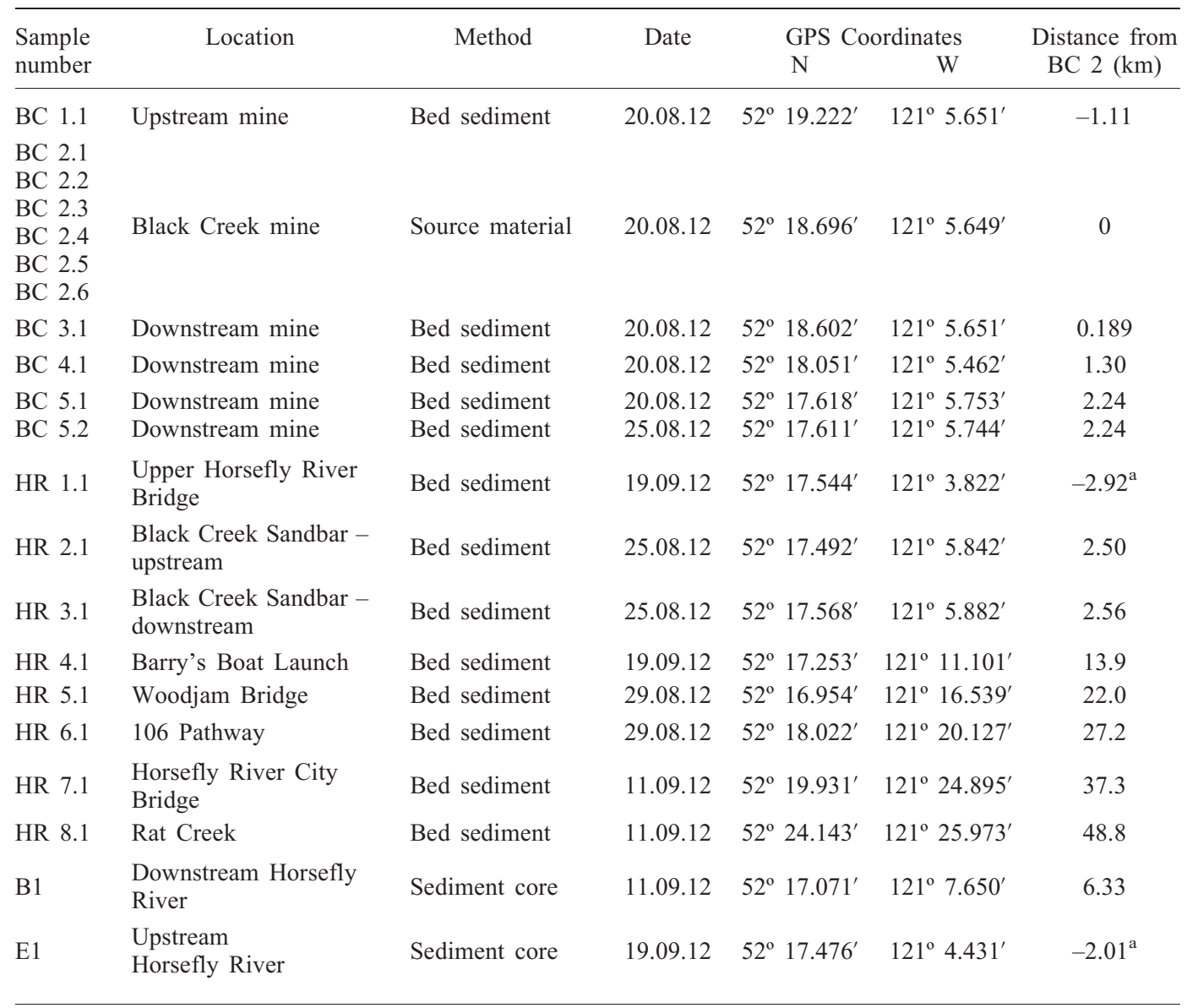

${ }^{\text {a }}$ Distance from the confluence of Black Creek and Horsefly River (HR 2).

contamination and redistribution. Sediment from the source rock material at the abandoned Black Creek mine was also sampled and consists of glacial and glaciofluvial sediments. To assess temporal changes in the geochemical composition of sediment transported and deposited below the mine, two sediment cores $\sim 65 \mathrm{~cm}$ long were taken from the Horsefly floodplain upstream and downstream from the Black Creek alluvial fan (Fig. 1). These cores were subsequently divided into $1 \mathrm{~cm}$ increments. Fine-grained sediment from the stream bed was sampled using a cylindrical plastic collection device with an open bottom. The fine bed sediment was agitated manually and resuspended into the water column contained within the sample device, thereby permitting the collection of water and sediment samples (for details, see Lambert and Walling, 1988). Water and the resuspended sediment were stored in 5-gallon ( 19 litre) containers until the sediment settled and the majority of water was siphoned off. Subsequently, the samples were centrifuged and the supernatant was discarded.

All sediment samples were air-dried and sieved to $<63 \mu \mathrm{m}$ for geochemical analysis of metals and metalloids (referred to hereafter as 'metals') including $\mathrm{Al}$, As, Cd, Se and $\mathrm{Zn}$. One set of floodplain core samples were sieved to $<2 \mathrm{~mm}$ for radiometric dating using $\mathrm{Pb}-210$ and $\mathrm{Cs}-137$ that were measured at Plymouth University, UK. Agedepth profiles were based on the Constant Rate of Supply (CRS) model to determine the ages of the 
cores' sediment layers (Appleby and Oldfield, 1983; Binford et al., 1993; Cohen, 2003; Mabit et al., 2014). Measurements of Cs- 137 were used to constrain the $\mathrm{Pb}$-210-based chronology (Mabit et al., 2014). The age-depth profiles were determined for the upper $30 \mathrm{~cm}$ of the cores, as these were the sections most relevant for this study (i.e. the last $\sim 100$ years).

The floodplain core sediment samples underwent microwave-assisted aqua regia digestion following the US EPA Method 3051A (US EPA, 2007) and pseudo-total element concentrations (ppm) were measured by inductively coupled plasma mass spectrometry (ICP-MS) at the ALS (Australian Laboratory Services) facility in Vancouver, Canada. The source and channel bed sediment samples were digested with aqua regia following the ISO 11466 protocol (DIN ISO 11466 , 1997), which is a commonly used method to determine amounts of elements in soils and sediment. These samples also underwent sequential extraction following the modified BCR (European Community Bureau of Reference) 3-step method, thereby enabling a comparison of the total amount of metal extracted with that obtained by aqua regia digestion (Rauret et al., 1999) resulting in the following geochemical phases: (1) acid-soluble, exchangeable and bound to carbonates; (2) reducible, bound to iron and manganese oxides; (3) oxidizable, bound to organic and sulfide compounds; and (4) residual (Byrne et al., 2010; Hass and Fine, 2010). Pseudototal concentrations $\left(\mathrm{mg} \mathrm{kg}^{-1}\right)$ in the extracts were then measured by inductively coupled plasma optical emission spectrometry (ICP-OES) at Utrecht University, The Netherlands. The acidsoluble, exchangeable and carbonate-bound phase (i.e. the first step) is the most susceptible to environmental changes, whereas the other three phases - the reducible $\mathrm{Fe} / \mathrm{Mn}$ oxide phase, the oxidizable, organic/sulfide phase and the residual phase - are increasingly less so.
Blanks and replicate samples were included in both methods of analysis for quality control. The replicate samples showed a coefficient of variation of the root mean square error (CVRMSE) of $<0.05$ for all metals measured, except for As concentrations in the aqua regia extracts, which had a CVRMSE of 0.11. Analysis of a select number of samples (both bed sediment and floodplain core) at both laboratories showed that the concentrations as measured by both methods correlated very well $(\mathrm{r}=0.998$ for As; 0.952 for Cd; 0.890 for Se; and 0.906 for $\mathrm{Zn}$ ). The concentrations for As and $\mathrm{Zn}$ from aqua regia digestion are generally slightly (up to $10 \%$ ) higher than from sequential extraction. The total Se concentrations from the sequential extraction were about a factor of two lower than from the aqua regia digestion. The total $\mathrm{Cd}$ concentrations from the sequential extraction were more than a factor of two higher than from the aqua regia digestion. Therefore, we excluded the $\mathrm{Cd}$ concentrations from sequential extraction from further analysis.

In order to quantify the influence of mining activities on the metal concentrations, a baseline was established for each metal by applying the lowest quantile regression analysis (Cade and Noon, 2003; Luoma and Rainbow, 2008). This method assumes that the lowest $25 \%$ of the floodplain cores' metal concentrations denote the pre-mining background levels (i.e. the average metal concentration due to the local geology). In the present case, this refers mainly to the sediment increments located deepest in the cores. To identify this quantile without the effect of grain size, metal concentrations were first normalized to Al concentrations - a common proxy for grain size variability of aluminosilicates (Loring, 1991; Luoma and Rainbow, 2008; van der Perk, 2013). Then, the corresponding observed metal concentrations of the lowest $25 \%$ were chosen for subsequent regression analysis, followed by baseline calculations for all metal concentrations:

TABLE 2. Slope (a) and intercept (b) values determined by lowest quantile regression analysis on the floodplain cores and used to calculate baseline concentrations of $\mathrm{As}, \mathrm{Cd}$, Se and $\mathrm{Zn}$.

\begin{tabular}{lcccr}
\hline & As & Cd & Se & Zn \\
\hline $\mathrm{a}$ & 4.280 & 0.093 & 0.198 & 28.940 \\
$\mathrm{~b}$ & 0.011 & 0.084 & 0.513 & 32.983 \\
$\mathrm{R}^{2}$ & 0.895 & 0.186 & 0.215 & 0.287 \\
Standard error & 0.538 & 0.060 & 0.144 & 11.331 \\
\hline
\end{tabular}




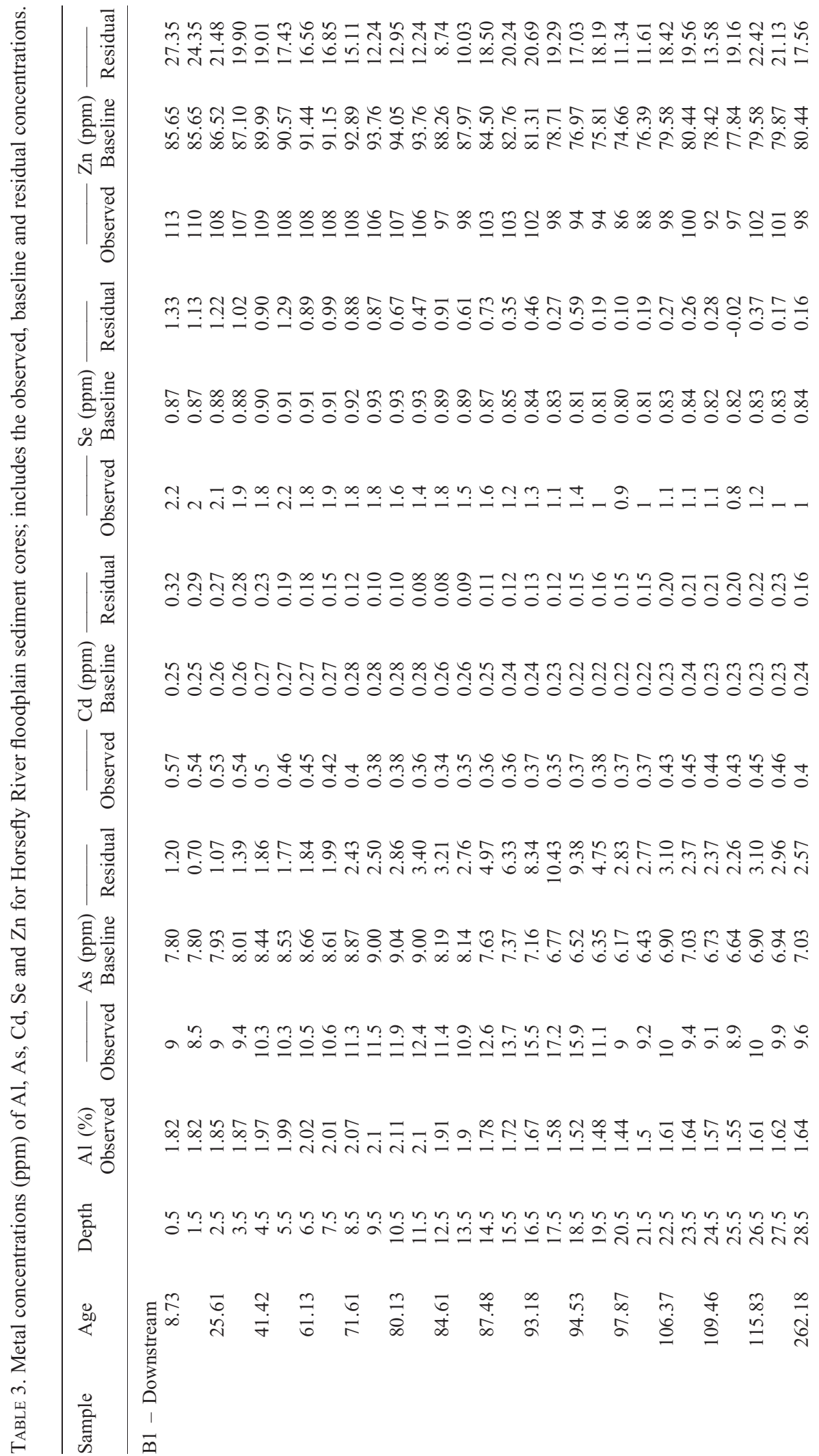




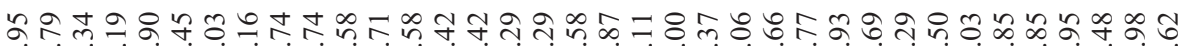

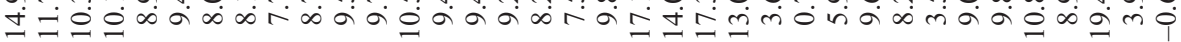

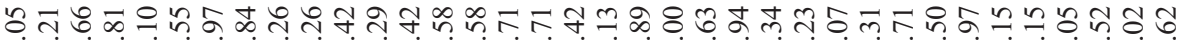

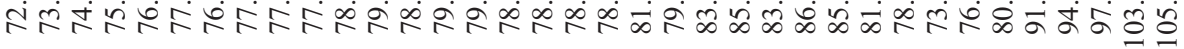

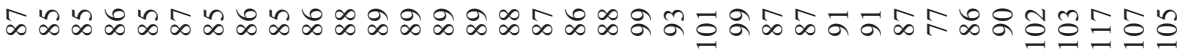

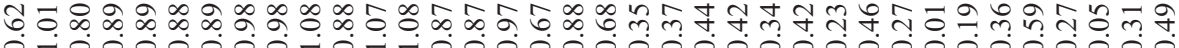
$0-0000000-0-100000000000000000000000$

๙ 00000000000000000000000000000000000.

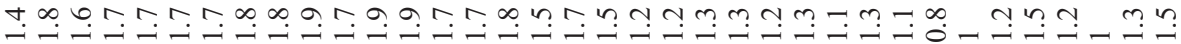

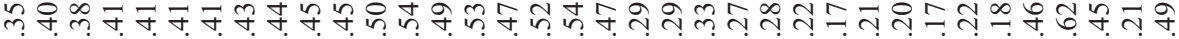

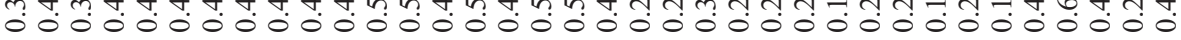

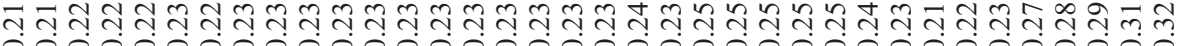
000000000000000000000000000000000000

请。

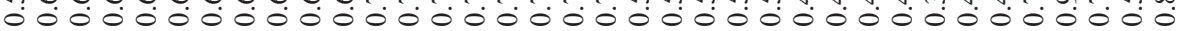

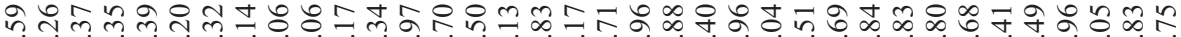

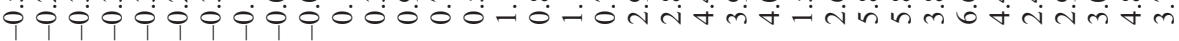

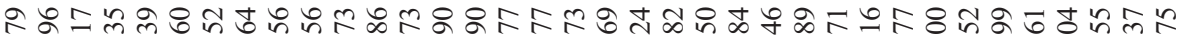

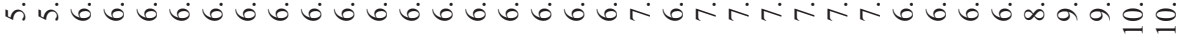
กี่

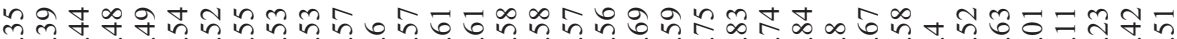

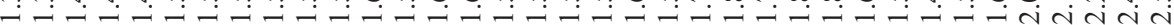

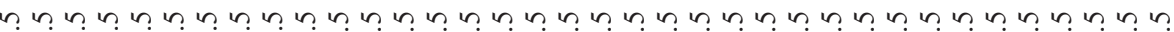
-

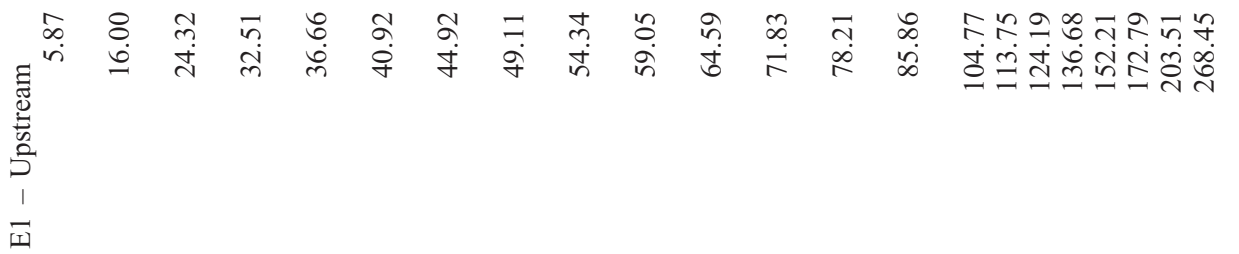


Baseline concentration $(\mathrm{ppm})=a^{*}[\mathrm{Al}]+b$,

where $a$ and $b$ are regression coefficients. Residual concentrations represent the remaining component of the total concentration and were presumed not to stem from the local geology, but from anthropogenic activities such as mining. These were calculated by subtracting the baseline concentrations from the total concentrations of the metal.

\section{Results and discussion}

The baseline parameter values (including $\mathrm{R}^{2}$ and standard error) based on the lowest quantile regression analysis of the cores are listed in Table 2 (see Table 3 for observed values). Figure 2 shows $\mathrm{As}, \mathrm{Cd}, \mathrm{Se}$ and $\mathrm{Zn}$ residual concentrations in the two dated sediment cores of the Horsefly floodplain upstream and downstream of the Black Creek alluvial fan. About 95 years ago, As concentrations peaked at more than twice the baseline concentration downstream of the Black Creek with no observable parallel peak in the upstream core; concentrations downstream have since decreased steadily over time. The increase in As concentrations at the time of mining is in agreement with the elevated values associated with the source material from the Black Creek mine site (site BC 2, Table 4). Both cores exhibit elevated levels of $\mathrm{Cd}, \mathrm{Se}$ and $\mathrm{Zn}$ during the past $50-70$ years compared to the established baselines. In the case of $\mathrm{Se}$ and $\mathrm{Zn}$, the residual concentrations for the cores downstream of the Black Creek confluence exceed those for the upstream cores. For $\mathrm{Cd}$, the concentrations in the upstream core generally exceed those for the downstream core, although concentrations for the uppermost sediment (i.e. present-day) are basically the same.

The residual concentrations of $\mathrm{As}, \mathrm{Cd}, \mathrm{Se}$ and $\mathrm{Zn}$ in stream-bed sediment are depicted (Fig. 3) relative to the distance to sample sites downstream of the Black Creek mine (mine samples are also included). Elevated concentrations of As are observed at the mine and the Black Creek; whereas along the Horsefly River, the As concentrations are close to the baseline value. $\mathrm{Cd}, \mathrm{Se}$ and $\mathrm{Zn}$ levels are generally higher in the stream-bed sediment of the Horsefly River than in the mine source material and Black Creek sediment.

The elevated As levels measured in the downstream core during the period of historically recorded mining activities, and the relatively high concentrations in source materials compared to contemporary sediment, suggests that the floodplain received substantial inputs of sediments derived from the Black Creek mine during the initial years of mine operation. The low current residual $\mathrm{Cd}, \mathrm{Se}$ and $\mathrm{Zn}$ levels in the bed sediment of Black Creek and in the mine source sediment and the absence of higher residual concentrations of these three metals during the initial years of mine operation indicate that the elevated concentrations in present-day samples from the Horsefly River and floodplain core sediments are probably unrelated to potential effects of the abandoned Black Creek mine. High Cd, Se and Zn levels in the core upstream of Black Creek suggest that

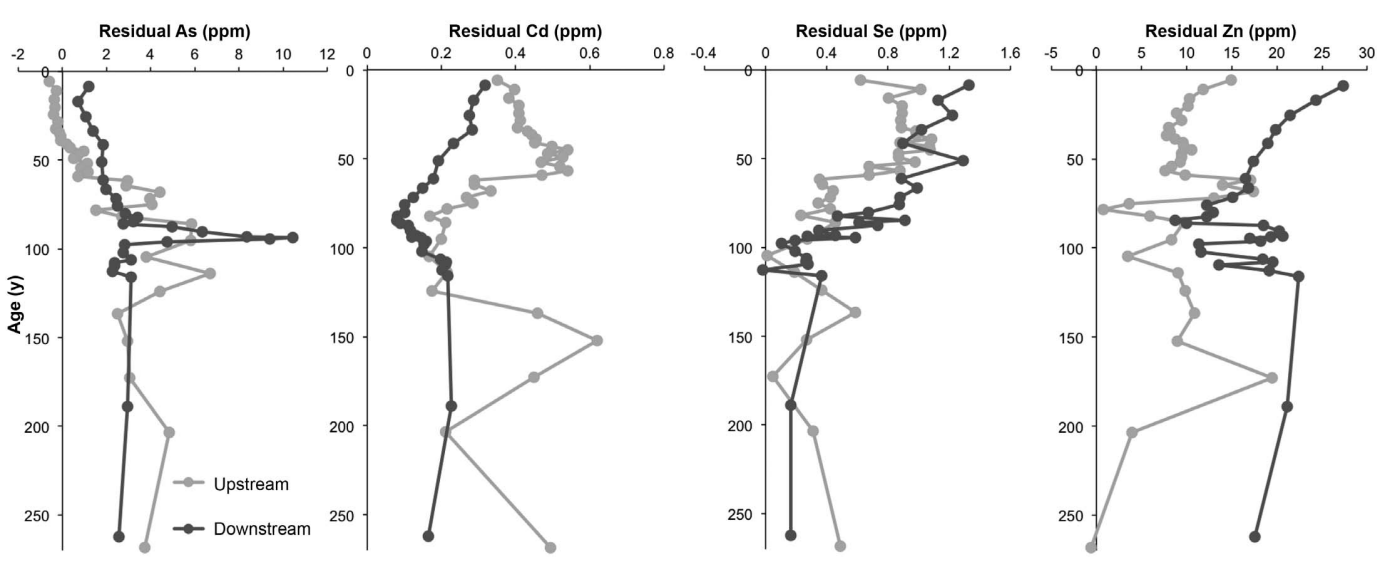

Fig. 2. Age (y) profiles for As, Cd, Se and $\mathrm{Zn}$ residual concentrations (ppm) of the upstream (light grey) and downstream (dark grey) floodplain sediment cores from the Horsefly River. 


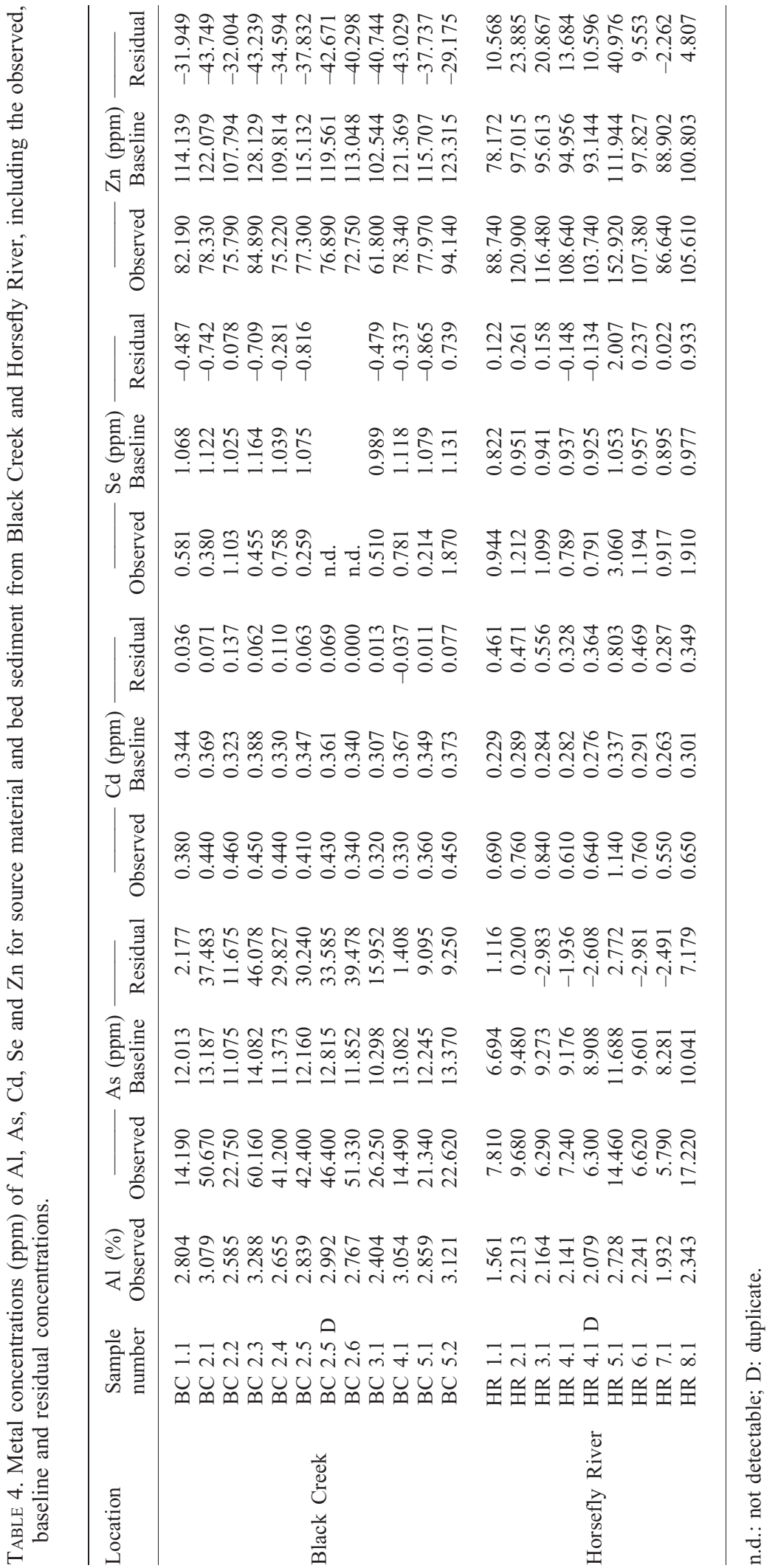



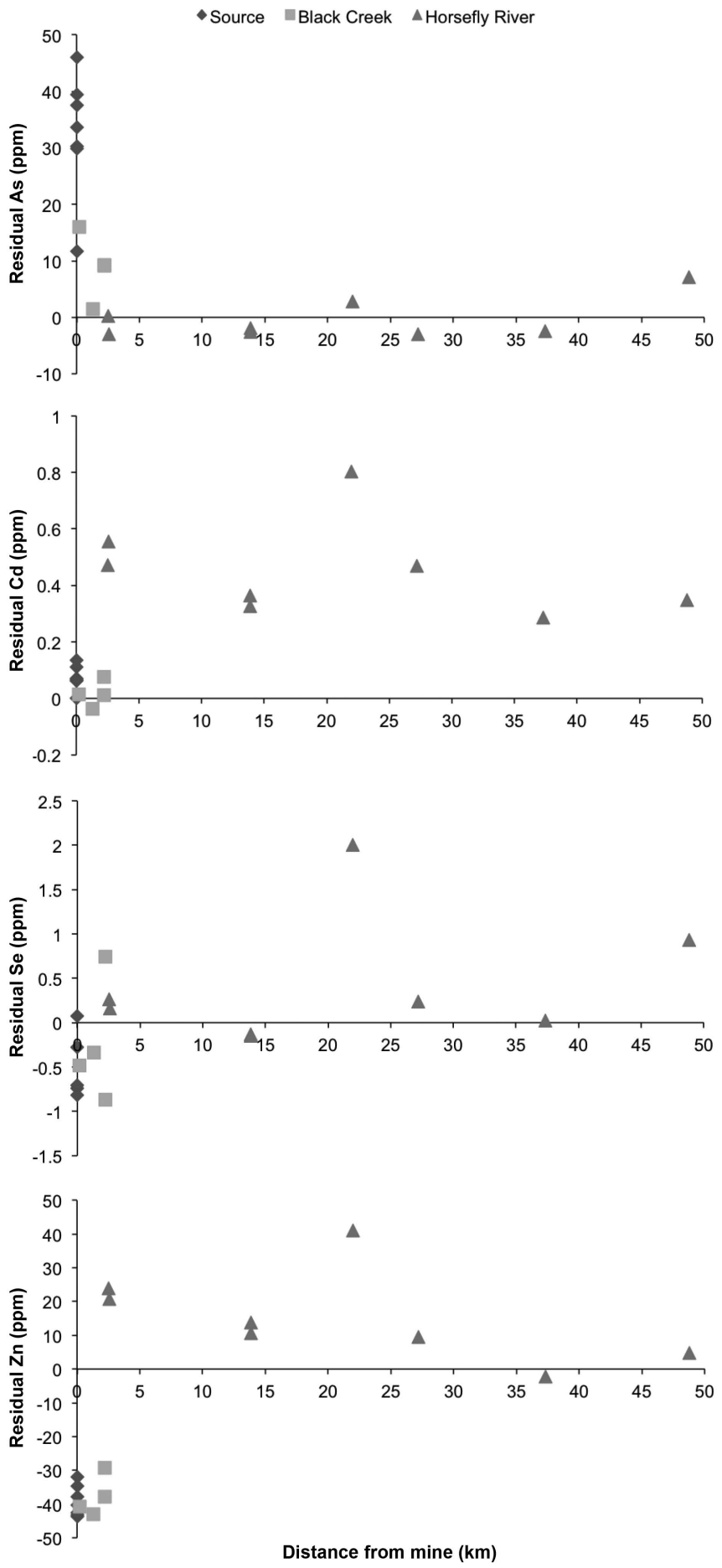

Fig. 3. Distance $(\mathrm{km})$ profiles of As, Cd, Se and $\mathrm{Zn}$ residual concentrations (ppm) of Black Creek (squares) and Horsefly River stream-bed sediment (triangles) as well as the source material from the abandoned mine (diamonds). 
exposed sediments at mines upriver are still releasing heavy metals into nearby surface waters.

Figure 4 shows the speciation of the metals in the channel bed sediments of Black Creek and the Horsefly River. The majority of As was measured in the residual fraction and in general $5-10 \%$ in the $\mathrm{Fe} / \mathrm{Mn}$ oxide fraction. In the samples where the Se was above the detection limit, the majority of Se was found in the oxidizable (sulfide and organic) fraction. This can be attributed to the fact that $\mathrm{Se}$ can substitute for $\mathrm{S}$ and has an affinity for metal sulfides (Drever, 1997; Luoma and Rainbow, 2008). Zn was in all four geochemical phases, although the largest amount was in the residual fraction.
As the majority of As and $\mathrm{Zn}$ concentrations were measured in the residual step of sequential extraction and the Se concentrations in the sulfide/ organic fraction, it implies that these metals are currently not mobile. This could potentially lead to secondary diffusion, but only when environmental conditions change drastically (e.g. redox potential, $\mathrm{pH}$, adsorption properties) (Luoma and Rainbow, 2008; van der Perk, 2013).

The observed metal concentrations were compared to Canadian sediment quality guidelines (BC Ministry of Environment, 2014; CCME, 1999); both interim (ISQG) and probable effect levels (PEL), as well as regional background levels of As and $\mathrm{Zn}$ from the $\mathrm{BC}$ Geochemical
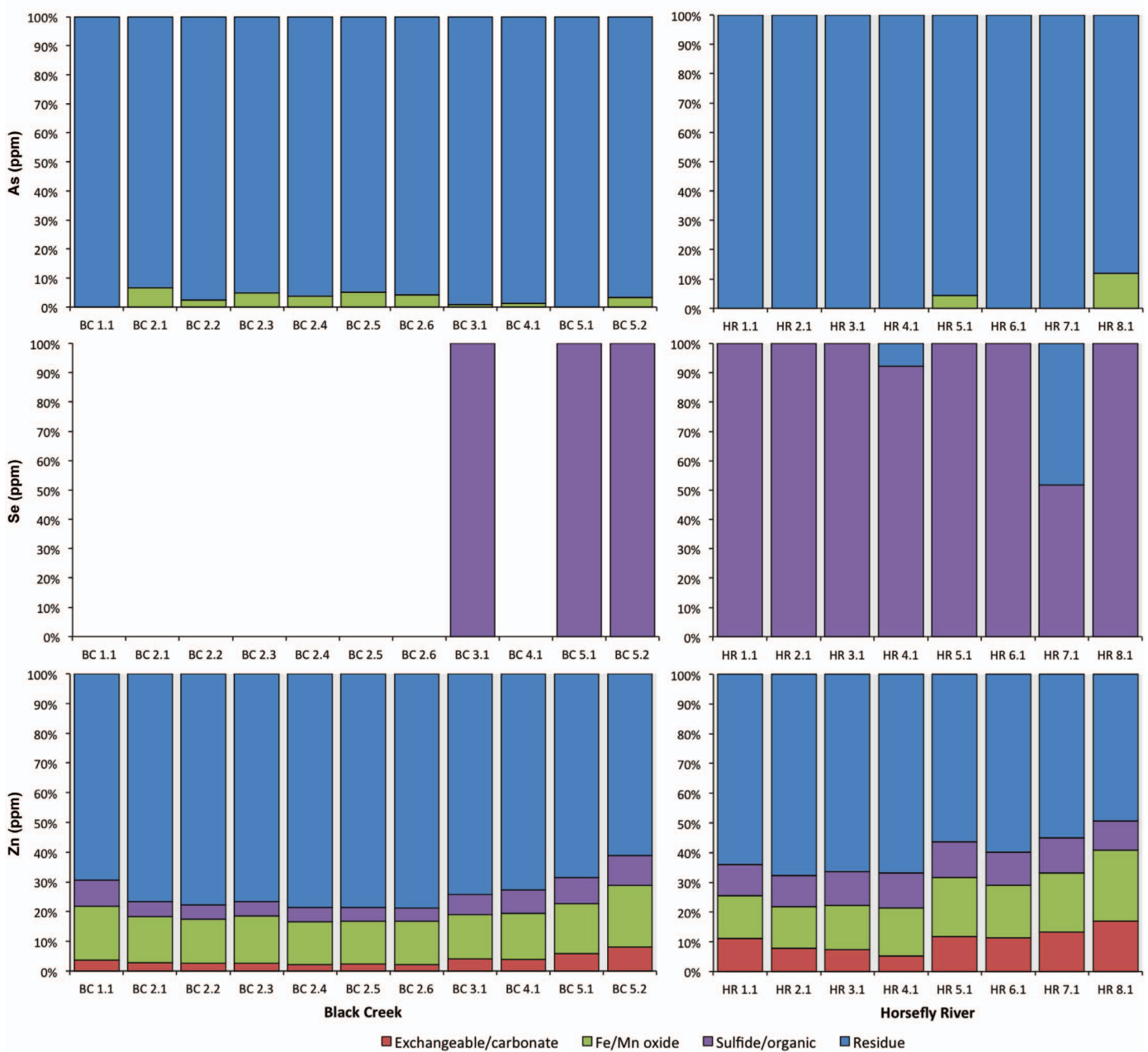

FIG. 4. Geochemical phases of As, Se and $\mathrm{Zn}(\%)$ for source material and bed sediment from Black Creek and Horsefly River. 
Atlas (Lett et al., 2008) (Table 5). Present-day observed concentrations of As in the Black Creek and Horsefly River and both sediment cores, in addition to $\mathrm{Cd}$ concentrations in the Horsefly River and the upstream core, are above the recommended ISQGs for aquatic life in freshwater. $\mathrm{Zn}$ concentrations for all samples, except the bed sediment at site HR 5, are below this threshold. While As and Cd concentrations in the Horsefly River are currently within PELs, As concentrations in the Black Creek as well as at the mine itself exceed this significantly.

The BC Ministry of Environment (2014) has recently updated its Se water-quality guidelines to include an alert concentration for sediments, thus providing an early indication of an increased risk of impacts to aquatic organisms. Based on this, only one site along the Horsefly River (site HR 5, $22 \mathrm{~km}$ from the mine) and some observed values from the downstream sediment core up to $\sim 60$ years ago $(6 \mathrm{~cm}$ depth) surpass this alert concentration.

Regional background levels of $\mathrm{As}$ and $\mathrm{Zn}$ are all lower than observed concentrations in the sediment core samples, with the exception of the upper upstream core up to $\sim 41$ years ago $(11 \mathrm{~cm}$ depth). Therefore, in terms of As and $\mathrm{Zn}$, there has been a history of locally raised levels in the Horsefly River basin compared to the encompassing Quesnel River basin.

\section{Conclusions}

The spatial and temporal patterns of selected metal concentrations in sediments of the Horsefly catchment suggest a slight, but not particularly widespread, effect from the Black Creek mine. During the first years of operation, the Black Creek mine caused local As contamination of the Horsefly River floodplain sediments $(6.3 \mathrm{~km}$ downstream from the mine), but contamination is presently contained in the Black Creek. The elevated concentrations of $\mathrm{Cd}, \mathrm{Se}$ and $\mathrm{Zn}$ in the Horsefly River are probably derived from upstream mining activities (Fig. 1) - either active or from the redistribution of contaminated stored sediments - as opposed to the Black Creek mine due to its inactivity and small size.

There are several documented abandoned mines and mineral prospects throughout the Horsefly watershed (Fig. 1) with potentially more undocumented, especially in upstream reaches. Additional research would be needed to better quantify the effect of mines on the entire watershed. While a small-scale, abandoned gold mine appears to have had a relatively local and short-lived impact on the metal content of finegrained sediment stored on floodplains and in the channel bed of the larger Horsefly system, the cumulative effect of several abandoned and recently active mines (Smith and Owens, 2014) may explain the elevated levels measured in the downstream reaches of the Horsefly watershed.

Establishing baseline levels of these metals is then crucial, especially considering that the regional background levels for As and $\mathrm{Zn}$ from the BC Drainage Geochemical Atlas are lower than the observed concentrations. Furthermore, given concerns associated with the erosion of floodplains due to climate changes, such stores of contaminated sediments may represent a secondary source of metals to aquatic systems:

TABLE 5. Canadian sediment quality guidelines (ISQG - interim sediment quality guidelines; PEL - probable effect levels) ( $\mathrm{mg} / \mathrm{kg} \mathrm{dw})$ and regional background levels (ppm).

\begin{tabular}{lccc}
\hline Metal & \multicolumn{2}{c}{$\begin{array}{c}\text { Canadian sediment quality guidelines } \\
\text { ISQG }\end{array}$} & Regional background levels $^{\mathrm{c}}$ \\
\hline $\mathrm{As}$ & 5.9 & 17 & $7( \pm 1.8)$ \\
$\mathrm{Cd}$ & 0.6 & 3.5 & \\
$\mathrm{Se}$ & - & $2^{\mathrm{b}}$ & $53( \pm 6.3)$ \\
$\mathrm{Zn}$ & 123 & 315 & \\
\hline
\end{tabular}

\footnotetext{
${ }^{\mathrm{a}}$ CCME (2014)

b BC Ministry of Environment (2014)

${ }^{c}$ Average values calculated for the Quesnel River basin by Smith and Owens (2014) based on data in the BC Drainage Geochemical Atlas (Lett et al., 2008)
} 
the so-called "chemical time bomb" (Miller and Orbock Miller, 2007).

\section{Acknowledgements}

This research is funded by the Association of Canadian Studies, Utrecht University and the University of Northern British Columbia (UNBC). The authors thank Sam Albers and Laszlo Enyedy of the Quesnel River Research Centre (QRRC) of UNBC for their support and guidance. Thanks are also extended to Ben Anderson Millington (UNBC and Plymouth University, UK) for his assistance and to the guest associate editor and three reviewers for their comments which improved this manuscript. This paper represents part of the QRRC Publication Series.

\section{References}

Albers, S.J. and Petticrew, E.L. (2012) Ecosystem response to a salmon disturbance regime: Implications for downstream nutrient fluxes in aquatic systems. Limnology \& Oceanography, 57, 113-123.

Appleby, P.G. and Oldfield, F. (1983) The assessment of ${ }^{210} \mathrm{~Pb}$ data from sites with varying sediment accumulation rates. Hydrobiologica, 103), 29-35.

Bailey, D.G. (1990) Geology of the central Quesnel Belt, British Columbia. BC Ministry of Energy, Mines and Petroleum Resources, Bulletin 97, Map 1, 1:100,000, Victoria, Canada.

BC Geological Survey (2014) MINFILE Mineral Inventory. BC Ministry of Energy, Mines and Petroleum Resources. http://minfile.gov.bc.ca.

BC Heritage Rivers Program (2014) Horsefly River. BC Ministry of Environment, www.env.gov.bc.ca.

BC Ministry of Environment (2014) Companion Document to: Ambient Water Quality Guidelines for Selenium Update. BC Ministry of Environment, Water Protection and Sustainability Branch. Victoria, Canada.

Binford, M.W., Kahl, J.S. and Norton, S.A. (1993) Interpretation of ${ }^{210} \mathrm{~Pb}$ profiles and verification of the CRS model in PIRLA project lake sediment cores. Journal of Paleolimnology, 9, 275-296.

Brown, C.E. (2002) World Energy Resources. Springer, Heidelberg, Germany.

Byrne, P., Reid, I. and Wood, P.J. (2010) Sediment geochemistry of streams draining abandoned lead/ zinc mines in central Wales: the Afon Twymyn. Journal of Soils and Sediments, 10, 683-697.

Cade, B.S. and Noon, B.R. (2003) A gentle introduction to quantile regression for ecologists. Ecological
Environment, 1, 412-420.

CCME (1999) Canadian sediment quality guidelines for the protection of aquatic life: Summary tables. In: Canadian Environmental Quality Guidelines, 1999. Canadian Council of Ministers of the Environment, Winnipeg, Canada.

Cohen, A.S. (2003) Paleolimnology: The History and Evolution of Lake Systems. Oxford University Press, Oxford, UK.

DIN ISO 11466 (1997) German standard procedure: Soil quality - extraction of trace elements soluble in aqua regia. Beuth Verlag GmbH: Berlin, Germany.

Drever, J.I. (1997) The Geochemistry of Natural Waters: Surface and Groundwater Environments. $3^{\text {rd }}$ edition. Prentice Hall, Saddle River, New Jersey, USA.

Du Laing, G., Vanthuyne, D.R.J., Vandecasteele, B., Tack, F.M.G. and Verloo, M.G. (2007) Influence of hydrological regime on pore water metal concentrations in a contaminated sediment-derived soil. Environmental Pollution, 147, 615-625.

Du Laing, G., Rinklebe, J., Vandecasteele, B., Meers, E. and Tack, F.M.G. (2009) Trace metal behaviour in estuarine and riverine floodplain soils and sediments: a review. Science of the Total Environment, 407, 3972-3985.

Environment Canada (2014) Water. Government of Canada, www.ec.gc.ca.

Environment Canada and Ministry of Environment, Lands and Parks. (1993) State of the environment report for British Columbia. Victoria, Canada.

Gilbert, R. and Desloges, J.R. (2012) Late glacial and Holocene sedimentary environments of Quesnel Lake, British Columbia. Geomorphology, 179, 186-196.

Hale, M. (1994) Handbook of Exploration and Environmental Geochemistry. Elsevier Science BV, The Netherlands.

Hass, A. and Fine, P. (2010) Sequential selective extraction procedures for the study of heavy metals in soils, sediments, and waste materials - a critical review. Critical Reviews in Environmental Science and Technology, 40, 365-399.

Horowitz, A.J. (1985) A Primer on Trace MetalSediment Chemistry. Lewis, Chelsea, Michigan, USA.

Horsefly Historical Society (1981) The Early History of a Cariboo Goldrush Community. www.harperscamp.ca.

Karimlou, G. (2011) Effects of mining on fine sediment quality: a comparison with regional metal background concentrations. MSc. thesis, Utrecht University, The Netherlands. http://dspace.library. uu.nl/handle/1874/207349.

Lambert, C.P. and Walling, D.E. (1988) Measurement of channel storage of suspended sediment in a gravelbed river. Catena, 15, 65-80. 
Lett, R., Nakeinishi, T., Desjardins, P., Man, E. and Mihalynuk, M. (2008) British Columbia Drainage Geochemical Atlas. BC Ministry of Energy, Mines and Petroleum Resources, GeoFile 2008-1:2008.

Lin, C., Tong, X., Lu, W., Yan, L., Wu, Y., Nie, C., Chu, C. and Long, J. (2005) Environmental impacts of surface mining on mined lands, affected streams and agricultural lands in the Dabaoshan mine region, southern China. Land Degradation and Development, 16, 463-474.

Loring, D.H. (1991) Normalization of heavy-metal data from estuarine and coastal sediments. ICES Journal of Marine Science, 1, 101-115.

Luoma, S.N. and Rainbow, P.S. (2008) Metal Contamination in Aquatic Environments: Science and Lateral Management. Cambridge University Press, New York, USA.

Mabit, L., Benmansour, M., Abril, J.M., Walling, D.E., Meusburger, K., Iurian, A.R., Bernard, C., Tarjan, S., Owens, P.N., Blake, W.H. and Alewell, C. (2014) Excess lead-210 as a soil and sediment tracer in catchment sediment budget investigations: a review. Earth-Science Reviews, 138, 335-351.

Miller, J.R. and Orbock Miller, S.M. (2007) Contaminated Rivers: a GeomorphologicalGeochemical Approach to Site Assessment and Remediation. Springer, Heidelberg, Germany.

Morel, F. (1983) Principles of Aquatic Geochemistry. John Wiley and Sons, Chichester, UK.

Panteleyev, A. and Hancock, K.D. (1988) Quesnel
Mineral Belt: Summary of the Geology of the Beaver Creek - Horsefly River Map Area. BC Ministry of Energy, Mines and Petroleum Resources, Geological Fieldwork, pp. 156-166.

Rauret, G., Lopez-Sanchez, J.F., Sahuquillo, A., Rubio, R., Davidson, C., Ure, A. and Quesvauviller, $\mathrm{Ph}$. (1999) Improvement of the BCR three step sequential extraction procedure prior to the certification of new sediment and soil reference materials. Journal of Environmental Monitoring, 1, 57-61.

Smith, T.A. and Owens, P.N. (2014) Individual and cumulative effects of agriculture, forestry and metal mining activities on the metal and phosphorus content of fine-grained sediment; Quesnel River basin, British Columbia, Canada. The Science of the Total Environment, 496, 435-442.

Surveys and Mapping Branch (1976) Prince George Dawson Creek. Canada Department of Mines, Energy and Resources, N.T.S. No. 93 N.E., 1:500,000. Ottawa, Canada.

US EPA (2007) Method 3051a: Microwave assisted acid digestion of sediments, sludges, soils, and oils. US Government Printing Office, Washington DC, USA. van der Perk, M. (2013) Soil and Water Contamination, 2nd edition. CRC Press, Boca Raton, Florida, USA.

van Lipzig, M.L.H.M. (2011) Effects of mining on the geochemistry of fine sediments in streams: a study in the Quesnel River catchment. MSc thesis, Utrecht University, The Netherlands. http://dspace.library.nl/ handle/1874/217188. 